\title{
Major complications of coronary arteriography: the place of cardiac surgery
}

\author{
J T Stewart, H H Gray, D E Ward, C W Pumphrey, D R Redwood, D J Parker
}

\begin{abstract}
The records of the catheter laboratory at St George's Hospital between 1983-1988 were reviewed to determine how often emergency coronary bypass surgery was performed because of a complication arising during elective coronary arteriography. A total of 11216 cardiac procedures were performed; 5781 were confined to left ventricular angiography and coronary arteriography in patients with suspected coronary artery disease. Fourteen patients, whose investigation had been considered routine, suffered profound circulatory collapse during the procedure. Emergency cardiac surgery was undertaken in 13 , with long term survival in 10 .

This experience suggests that, even in patients considered to be at low risk, there were major complications requiring emergency coronary surgery in at least 2.4 per 1000 coronary arteriograms performed. Survival after emergency cardiac surgery in these patients was $77 \%$. These findings and the access to cardiac surgery should be considered when the development of facilities for cardiac catheterisation is planned.
\end{abstract}

In Britain facilities for cardiac catheterisation have developed alongside those of cardiac surgery, usually within the same hospital. In recent years, however, the demand for cardiological services, both invasive and non-invasive, has expanded and it has been suggested that there should be greater responsibility for investigation and treatment in the district general hospitals. Under such a system, district cardiologists, many of whom are trained in invasive techniques, would be responsible for certain procedures that have traditionally been performed in the referral centres, such as permanent pacemaker implantation, and "low risk" diagnostic cardiac catheterisation.

Underlying this policy is the assumption that the risks of catheterisation without surgical back up at the same site would be negligible, because those patients who were clearly at high risk from the procedure, such as patients with unstable symptoms or pulmonary oedema, would still be studied at the referral centres. While it is true that most high risk patients can be identified readily, several major complications of cardiac catheterisation, for which emergency cardiac surgery may be indicated, are unpredictable.

\section{Method}

We reviewed the records of our cardiac catheter laboratory to determine the frequency of unexpected major complications leading to emergency cardiac surgery. We restricted our review to patients being investigated because of chest pain (with left ventriculography and coronary arteriography) in an attempt to establish the probable minimum risk.

\section{Results}

The records of the cardiac catheter laboratory at St George's Hospital, London for the years 1983-1988 were reviewed. In the 6 years studied, 11216 cardiac procedures were performed. Left ventricular angiography and coronary arteriography in patients with suspected coronary artery disease was the sole investigation in 5781 cases $(79 \%$ men, $21 \%$ women). The remaining 5435 patients underwent pacing procedures, electrophysiological studies, pericardial tap, percutaneous coronary angioplasty, endomyocardial biopsy, or were investigated for the assessment of valve disease (including percutaneous balloon dilatation of valves), or after previous coronary artery bypass surgery. Patients who were clearly at a higher risk from coronary arteriography, such as those with post-infarction ventricular septal defects $(n=31)$, were also excluded from this analysis. Included in the 5781 , however, is an unknown number of patients who were studied as emergencies because of unstable angina, but who had no catheter-related complication.

Eighteen $(0.3 \%)$ of the 5781 patients were referred for urgent operation because of acute coronary dissection $(n=6)$, acute coronary occlusion $(n=7)$, severe global ischaemia (defined as persistent electrocardiographic change, chest pain, and hypotension after contrast injection into the coronaries $(n=3)$, or deterioration of pulmonary oedema $(n=2$, left ventriculography not performed). In each case the decision to request urgent surgical assistance was made by a consultant cardiologist.

Retrospective review of the case notes showed that four patients (three men, one \\ Cardiac Department,
St George's Hospital, \\ J T Stewa \\ C W Pumphrey \\ Cardiac Department, \\ Cardiothoracic \\ Centre, Southampton
}


Nature of complications of arteriography and outcome after emergency operation

\begin{tabular}{|c|c|c|c|c|c|}
\hline Patient & Route & $C A D$ & Complication & Outcome & Postoperative ECG \\
\hline 1 & Femoral & $\begin{array}{l}\text { 2VD } \\
\text { (LAD and } C x)\end{array}$ & $\begin{array}{l}\text { Occluded LMS. } \\
\text { Hypotension }\end{array}$ & Sternal abscess & Generalised $T$ wave flattening \\
\hline 2 & Brachial & $?$ & $\begin{array}{l}\text { Dissection LMS. } \\
\text { Hypotension, ECM }\end{array}$ & Symptom free & Loss of $R$ wave voltage in anterior leads \\
\hline 3 & Femoral & $?$ & Occluded LMS. & Symptom free & Loss of $R$ wave voltage in anterior leads \\
\hline 4 & Femoral & SVD (LAD) & $\begin{array}{l}\text { Dissection LMS. } \\
\text { Hypotension, ECM }\end{array}$ & $\begin{array}{l}\text { Reduced effort tolerance. } \\
\text { Impaired LV function }\end{array}$ & Anterior $Q$ waves \\
\hline 5 & Brachial & $3 V D$ & $\begin{array}{l}\text { Asystole, and hypotension } \\
\text { with RCA injection. Paced }\end{array}$ & Symptom free & No change \\
\hline 6 & Brachial & SVD (LAD) & $\begin{array}{l}\text { Cx dissection. Anterior } \\
\text { ST segment elevation. } \\
\text { Pain, hypotension }\end{array}$ & Symptom free & Anterior $Q$ waves \\
\hline 7 & Brachial & $\begin{array}{l}\text { 2VD } \\
\text { (LAD and } O M \text { ) }\end{array}$ & $\begin{array}{l}\text { RCA dissection. Inferior } \\
\text { ST segment elevation }\end{array}$ & Symptom free & No change \\
\hline 8 & Femoral & $\begin{array}{l}\text { 3VD with } \\
\text { LMS stenosis }\end{array}$ & $\begin{array}{l}\text { Hypotension and } \\
\text { bradycardia }\end{array}$ & Symptom free & No change \\
\hline 9 & Femoral & $\begin{array}{l}\text { 2VD } \\
\text { (LAD and RCA) }\end{array}$ & $\begin{array}{l}\text { Occluded LAD. } \\
\text { Anterior ST segment } \\
\text { elevation. Hypotension }\end{array}$ & $\begin{array}{l}\text { No cardiac symptoms. } \\
\text { Pedal gangrene }\end{array}$ & Anterior $\mathrm{Q}$ waves \\
\hline 10 & Brachial & $3 V D$ & $\begin{array}{l}\text { Cx occlusion. Pain. } \\
\text { Hypotension. Widespread ST } \\
\text { segment depression }\end{array}$ & Symptom free & Loss of $R$ wave voltage in anterior leads \\
\hline 11 & Brachial & $3 V D$ & $\begin{array}{l}\text { Hypotension and VF } \\
\text { after LV angiogram. ECM }\end{array}$ & Died on bypass & \\
\hline 12 & Brachial & $\begin{array}{l}\text { 3VD with } \\
\text { LMS stenosis }\end{array}$ & $\begin{array}{l}\text { LMS dissection. Hypotension. } \\
\text { ECM. Widespread ST } \\
\text { segment elevation }\end{array}$ & $\begin{array}{l}\text { Died } 2 \text { days postop. } \\
\text { Persistent low output state }\end{array}$ & $\begin{array}{l}\text { Anterior } Q \text { waves } \\
\text { RBBB }\end{array}$ \\
\hline 13 & Brachial & $?$ & $\begin{array}{l}\text { LMS dissection. } \\
\text { Hypotension, asystole }\end{array}$ & $\begin{array}{l}\text { Died } 6 \text { weeks postop. } \\
\text { Below knee amputation, } \\
\text { low output state }\end{array}$ & Anterior $Q$ waves \\
\hline
\end{tabular}

LMS, left main stem coronary artery; LAD, left anterior descending coronary artery; Cx, circumflex coronary artery; RCA, right coronary artery; OM, obtuse marginal branch of circumflex coronary artery; ECM, external cardiac massage; LV, left ventricular; VF, ventricular fibrillation; RBBB, right bundle branch block; SVD, single vessel disease; $2 \mathrm{VD}$ and $3 \mathrm{VD}$, two and three vessel coronary artery disease.

woman; age 56-74, mean 64 years) had clearly been at high risk before the procedure. All had continuing chest pain despite maximal medical treatment, and three had pulmonary oedema at the time of catheterisation. All underwent emergency coronary artery bypass surgery, but none survived to leave hospital. These high risk patients are excluded from further analysis.

In the remaining fourteen patients $(0 \cdot 24 \%$ of the total) who were referred for urgent surgery (eight men, six women; age 43-70, mean 59 years) the investigation had been considered routine and eight were day case procedures. Acute coronary dissection occurred in six $(43 \%)$, acute coronary occlusion in five $(36 \%)$, and global ischaemia in three $(21 \%)$.

There was multivessel coronary artery disease in eight $(57 \%)$ patients, but significant left main coronary artery stenosis was seen in only two patients. There was obstruction of the left main coronary artery (from either dissection or occlusion without dissection) in six $(43 \%)$ : in three the proximal coronary anatomy remains unknown, one had severe triple vessel disease without significant left main disease, and in the other two there was relatively minor disease (table).

In five $(36 \%)$ patients the exact coronary anatomy had not been established at the time of collapse; one had a cardiac arrest after the left ventriculogram and could not be resuscitated, and in the other four there was occlusion or dissection (with persistence of contrast) of the left main coronary artery after the initial left coronary injection. Postmortem study of two of these five patients showed triple vessel coronary disease (including left main stem disease in the patient who collapsed after ventriculography alone).

Twelve patients $(86 \%)$ went immediately in the operating theatre for emergency coronary artery bypass surgery, one patient $(7 \%)$ died in the catheter laboratory before transfer to theatre was possible, and one patient ( $7 \%$ ) underwent operation 2 hours after cardiac catheterisation. Seven $(58 \%)$ of the 12 who had immediate operations required full resuscitation procedures, including external cardiac massage, during transit from the catheter laboratory to the operating theatre; the other five $(42 \%)$ remained appreciably hypotensive, but with a stable rhythm and cardiac output until the start of cardiopulmonary bypass.

After emergency operation three $(23 \%)$ patients died in hospital and the $10(77 \%)$ who survived were alive at long term follow up. The three postoperative deaths occurred in the group of patients who had required cardiac massage until the establishment of cardiopulmonary bypass.

The catheter operator was a consultant cardiologist in seven $(50 \%)$ cases, a senior registrar in three $(21 \%)$ cases, and a registrar in four $(29 \%)$ cases. To put these figures in perspective, $45 \%$ of all procedures are performed by three consultant cardiologists, $20 \%$ by the senior registrar, and $35 \%$ by registrars. The femoral approach was used in $\operatorname{six}(43 \%)$ of the 14 patients, while the brachial approach (using a preformed brachial catheter) was used in the remaining eight $(57 \%)$ patients. Overall, $70 \%$ of elective coronary arteriograms are performed via the femoral artery and 30\% via the brachial artery at St George's Hospital.

There were postoperative complications in three $(30 \%)$ of the 10 survivors. One patient who had required support with an intra-aortic balloon pump while cardiopulmonary bypass was stopped, later had peripheral gangrene, but did not require further operation. She had not experienced any cardiac symptoms when seen postoperatively in outpatients, but she died suddenly 2 years after operation. This was the only late death. One man experienced episodes 
of infection of the sternal wound, which required operative debridement, and the third had clearly suffered an extensive anterior myocardial infarct resulting in left ventricular dysfunction. When seen in outpatients he had reduced effort tolerance, although his symptoms were stable on treatment with a diuretic and an angiotensin converting enzyme inhibitor. The remaining nine patients $(90 \%)$ were free of cardiac symptoms when reviewed in the outpatient clinic, although in six $(60 \%)$ there were changes in the postoperative electrocardiogram consistent with infarction (table).

\section{Discussion}

The risks of cardiac catheterisation and angiography are well recognised. These are usually divided into minor problems such as transient chest pain or arrhythmia and major complications such as arterial injury and embolisation, stroke, myocardial infarction, and death. There has been debate over the relative safety of the brachial and femoral routes for cardiac catheterisation. ${ }^{1-3}$ The data presented here seem to suggest that there is a greater risk of major complication when the brachial approach is used. However, in this retrospective survey we made no attempt to match the groups and they may not be directly comparable. It is our usual policy to catheterise day patients from the arm, but patients with generalised arterial disease, which includes iliofemoral disease, are more likely to be studied from the brachial route. Such patients are more likely to have severe multivessel coronary disease and may be at higher risk irrespective of the approach used. ${ }^{24}$

In 1972, the ad hoc Committee on Coronary Artery Surgery of the Inter-Society Commission for Heart Disease Resources recommended that deaths associated with coronary arteriography, in the United States of America, should not exceed $0 \cdot 3 \% .^{5}$ In 1974, Judkins and Gander suggested that a mortality rate in excess of $0.1 \%$ was unacceptable, ${ }^{1}$ but later reports have shown that, when all cases are considered, most laboratories have a mortality of $0.1-0.2 \% .^{467} \mathrm{It}$ is clear, however, that the risk to the patient is closely related to his functional class and the severity of coronary artery disease. Left main stem disease is said to increase the risk of death by 6.8 times, and factors such as unstable angina, congestive heart failure, multiple ventricular extrasystoles, and hypertension also increase the risk. ${ }^{2}$ Triple vessel disease and age greater than 60 years have also been associated with increased mortality in one report. ${ }^{4}$

Conversely, it has been suggested that in low risk patients (functional class I and II of the New York Heart Association classification) mortality may be as low as $0.02 \% .^{7}$ In a paper presented recently to the British Cardiac Society, it was suggested that invasive cardiac investigations, and even coronary angioplasty, could be performed safely in the absence of on site cardiac surgery. ${ }^{8}$ The numbers in this study were very small, however (273 diagnostic coronary arteriograms and six coronary angioplasties), and as a result its conclusions must be interpreted with caution. The delay before emergency operation could be undertaken at another hospital, in the two patients in whom it was required, was 3 hours. A recent paper reporting the results of cardiac catheterisation as a day case procedure is relevant to this issue ${ }^{9}$ Oldroyd et al reviewed 900 patients selected for day case catheterisation, and therefore, by definition, considered to be at low risk from the procedure ( $56 \%$ had one or two vessel disease). Forty patients $(4.4 \%)$ could not be discharged the same day because of some complication of the procedure or because urgent, but not immediate, coronary artery surgery was considered necessary. For the group as a whole the incidence of death was $0.2 \%$, non-fatal myocardial infarction $0.7 \%$, and major vascular injury $0.2 \%$. Mortality was $0.3 \%$ in the subgroup that underwent coronary angiography and left ventriculography alone. It was not stated how many patients underwent immediate operation from this series.

Our findings accord with those of Oldroyd $e t$ al. We believe that without the benefit of emergency cardiac surgery at least 10 of our 14 "low risk" patients would have died. Thus while mortality for elective left ventriculography and coronary arteriography was $<0.1 \%$ in our series, it would almost certainly have been $\geqslant 0.2 \%$ had we not had recourse to emergency surgery. It is of course impossible to prove that the patients referred for emergency operation benefited from its availability, but the severity of haemodynamic disturbance seen makes it very likely that they would have died without operation. Furthermore, despite the experience of Bayliss et al, we believe that there would not have been time to transfer these patients elsewhere for operation.

Survival after emergency operation in this group of patients was $77 \%$ and in most left ventricular function, judged by symptomatic criteria, was adequate. That there were no survivors in patients identified as being at high risk suggests that heroic attempts to resuscitate such patients may be inappropriate.

By restricting our survey to the simplest type of left heart investigation, which is likely to form the greatest part of the workload of any cardiac catheter laboratory, we believe that we have shown the minimum risk of major unexpected complications. If patients with unstable symptoms, heart failure, complex congenital disease, or valve disease were included the risk is likely to be higher. Unfortunately, we cannot tell from this retrospective review of the catheter laboratory records how many other patients who would have been considered high risk because of unstable symptoms had uneventful coronary arteriography. By reducing the size of the denominator, the exclusion of such patients would have resulted in an even higher calculated risk.

Our experience suggests that the mortality associated with cardiac catheterisation in patients perceived to be at low risk is likely to be greater than two patients in every 1000 . This may be reduced by having surgical facilities 
immediately available. These findings should be borne in mind when the development of new cardiac catheterisation facilities is considered; it may be more desirable to expand the existing facilities at the regional centres and to encourage their use by appropriately trained cardiologists from district hospitals.

1 Judkins MP, Gander MP. Prevention of complications of coronary arteriography. Circulation 1974;49:599-602.

2 Davis K, Kennedy JW, Kemp HG Jr, Judkins MP, Gosselin AJ, Killip T. Complications of coronary arteriography from the collaborative study of coronary artery surgery (CASS). Circulation 1979;59:1105-11.

3 Petch MC, Sutton R, Jefferson KE. Safety of coronary arteriography. Br Heart $J$ 1973;35:377-80.

4 Kennedy JW, Baxley WA, Bunnell IL, et al. Mortality related to cardiac catheterization and angiography. Cathet Cardiovasc Diagn 1982;8:323-40.

5 Report of Inter-Society Commission for Heart Disease Resources. Optimal resources for coronary artery surgery. Circulation 1972;46:A-325-39.

6 Bourassa MG, Noble J. Complication rate of coronary arteriography. A review of 5250 cases studied by a percutaneous femoral technique. Circulation 1976;53:106-14.

7 Kennedy JW. Complications associated with cardiac catheterisation and angiography. Cathet Cardiovasc Diagn 1982;8:5-11.

8 Bayliss J, Shakespeare C, Lincoln C, Sutton R. Does invasive cardiology require the presence of cardiac surgery? [Abstract] $\mathrm{Br}$ Heart $J$ 1987;57:79.

9 Oldroyd KG, Phadke KV, Phillips R, Carson PHM, Clarke $M$, Davis JAS. Cardiac catheterisation by the Judkin technique as an outpatient procedure. $\mathrm{Br}$ Med 1989;298:875-6.

\section{VIEWS FROM THE PAST Sir Henry Dale}

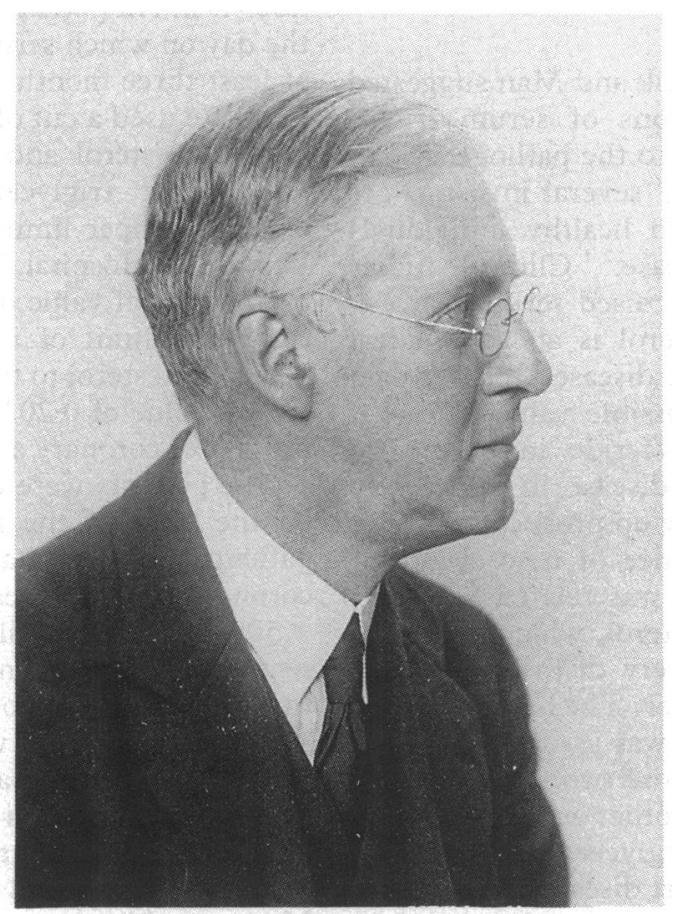

Immediately after qualifying in medicine Dale joined E H Starling in the physiology department at University College, London, and then spent 10 years at the newly established Wellcome Laboratories, where he became director. His early interest in the properties of ergot led him to study adrenaline, histamine, and acetylcholine at the National Institute of Medical Research, where he also became director. For his work on the chemical transmission of nerve impulses he shared the Nobel Prize in physiology or medicine with his friend Otto Loewi in 1936 (Lewis Collection).

DENNIS M KRIKLER 